\title{
Síndrome de Sézary. Tratamiento
}

\section{Sézary syndrome. Treatment}

Bárbara Alonso ${ }^{1}$, Mariana Arias ${ }^{1}$ y Alejandra Abeldaño ${ }^{2}$

\section{RESUMEN}

El síndrome de Sézary (SS) es una variante leucémica del linfoma cutáneo de células T con mal pronóstico, que requiere un abordaje multidisciplinario. El tratamiento es paliativo, ya que no se conoce la curación para esta enfermedad. El objetivo terapéutico es reducir al mínimo las recurrencias y preservar la calidad de vida y la supervivencia global. Si bien se cuenta con numerosas opciones, las terapias inmunomoduladoras son las de elección. La quimioterapia se reserva para los casos refractarios 0 ante la progresión de la enfermedad.

Palabras clave: síndrome de Sézary, fototerapia, fotoféresis extracorpórea, retinoides, interferón.

Dermatol. Argent. 2020, 26 (2): 50-57

\section{ABSTRACT}

Sézary syndrome (SS) is a leukemic cutaneous T-cell lymphoma with poor prognosis that requires a multidisciplinary approach. Treatment is palliative, because there is no cure for SS. The aim of treatment is minimizing disease recurrence, preservation of quality of life and overall survival. There are many options, but immunomodulatory therapies are tried first. Chemotherapy is reserved for refractory or progressive disease. Key words: Sézary syndrome, phototherapy, extracorporeal photopheresis, retinoids, interferon.

Dermatol. Argent. 2020, 26 (2): 50-57

\footnotetext{
${ }^{1}$ Médica Dermatóloga

2 Jefa de la Unidad de Dermatología

Unidad de Dermatología, Hospital General de Agudos Dr. Cosme Argerich, Ciudad Autónoma de Buenos Aires, República Argentina
}

Contacto del autor: Bárbara Alonso E-mail: barby_alonso@hotmail.com Fecha de trabajo recibido: $1 / 6 / 2020$ Fecha de trabajo aceptado: 29/6/2020 Conflicto de interés: las autoras declaran que no existe conflicto de interés.
Existen escasos estudios controlados que avalan las decisiones terapéuticas para el SS, por lo que en reiteradas oportunidades el tratamiento depende de su asequibilidad y de la experiencia de los profesionales tratantes ${ }^{1}$. Por tal motivo, la European Organisation for Research and Treatment of Cancer (EORTC) estableció recientemente un consenso de recomendaciones para el tratamiento de la micosis fungoide y del SS, en el que tuvo en cuenta la evidencia científica publicada y la opinión de expertos de múltiples países europeos, para lograr una adecuada decisión terapéutica en la práctica clínica. También se encuentra una guía clínico-práctica de la National Comprehensive Cancer Network (NCCN) para el tratamiento de los linfomas cutáneos de células $\mathrm{T}$ (LCCT). En 2011, Olsen et ál. publicaron una revisión acerca de la inmunopatogenia, el tratamiento y las recomendaciones terapéuticas del United States Cutaneous Lymphoma Consortium (USCLC) (Tablas 1 y 2). En el año 2019 se publicó la actualización del consenso de linfomas cutáneos de la Sociedad Argentina de Dermatología ${ }^{1-4}$. 


\section{Monoterapia}

Fotoféresis extracorpórea
INF- $\alpha$
Bexaroteno
Bajas dosis de metotrexato ( $\leq 100 \mathrm{mg} /$ semana)
\[ \text { Tratamiento combinado } \]
Tratamiento dirigido a la piel + sistémico:
- INF- $\alpha+$ PUVA o mostaza nitrogenada tópica
- metotrexato (dosis bajas) + mostaza nitrogenada tópica
- bexaroteno + PUVA
- inmunomoduladores (fotoféresis extracorpórea, INF- $\alpha$, bexarote-
no solos o combinados) + electron beam corporal total (TSEB)
Tratamientos sistémico + sistémico
- INF- $\alpha+$ bexaroteno
- fotoféresis extracorpórea + otra terapia inmunomoduladora
(bexaroteno, INF- $\alpha$, INF- $\gamma$, metotrexato (dosis bajas), solos o com-
binados)
- metotrexato (dosis bajas) + INF- $\alpha$

TABLA 1: Tratamiento de primera línea del síndrome de Sézary recomendado por Olsen et áß.

Alemtuzumab
Clorambucilo + glucocorticoide
Doxorrubicina liposomal
Inhibidores de la histona-desacetilasa (iHDAC)
Gemcitabina
Altas dosis de metotrexato (> $100 \mathrm{mg} /$ semana)
Fludarabina +/- ciclofosfamida
Mecloretamina
Trasplante alogénico
Ensayos clínicos

TABLA 2: Tratamiento de segunda línea del síndrome de Sézary recomendado por Olsen et áp.

El SS requiere un manejo multidisciplinario conformado por especialistas en dermatología, dermatopatología, oncohematología y radioterapia ${ }^{5}$.

El principal objetivo de la terapéutica es mejorar la sintomatología, lograr remisiones prolongadas y optimizar la calidad de vida, ya que los tratamientos no tienen fines curativos ${ }^{1,5-7}$.

Como se trata de la expresión leucémica de un LCCT eritrodérmico, se prefiere el tratamiento sistémico desde el principio ${ }^{8-10}$. Se recomienda el tratamiento combinado, en lo posible un inmunomodulador asociado a uno dirigido a la piel, ya que suele tener más eficacia que la monoterapia. La elección terapéutica depende del estadio, la sintomatología, las comorbilidades y la asequibilidad a los tratamientos ${ }^{3,7,10}$.
La NCCN agregó a los tratamientos de primera línea los inhibidores de la histona desacetilasa (iHDAC), que pueden usarse como monoterapia o combinados ${ }^{2}$.

El tratamiento es crónico. Se debe mantener la terapia instaurada ante una buena evolución para optimizar su duración. En caso de recidiva, se sugiere reiniciar la misma terapéutica, ya que suele obtenerse una respuesta favorable. Ante una respuesta parcial, evaluar el cambio de terapia dentro de las opciones de primera línea antes de instaurar un tratamiento de enfermedad refractaria. En caso de tratarse de una enfermedad resistente a los tratamientos de primera línea o de progresión de la enfermedad, se tienen en cuenta las opciones de segunda línea de Olsen et ál ${ }^{3}$.

La EORTC coincide en gran parte con las recomendaciones de los dos trabajos mencionados, pero difiere en considerar el clorambucilo asociado a los glucocorticoides entre los tratamientos de primera línea ${ }^{1}$.

A continuación, se detallan las opciones terapéuticas propuestas.

\section{TRATAMIENTOS DIRIGIDOS A LA PIEL}

\section{Glucocorticoides tópicos}

Los glucocorticoides tópicos y sistémicos resultan pilares en el tratamiento del SS, por su efecto antiinflamatorio y apoptótico de los linfocitos tumorales, aunque se asocian a un empeoramiento si se los suspende ${ }^{3}$.

\section{Fototerapia}

Es efectiva en combinación con el tratamiento sistémico. Provoca daño al ADN, apoptosis de las células tumorales y disminución de las células de Langerhans y de la secreción de citoquinas de los queratinocitos ${ }^{5,11}$.

UVB de banda angosta (311 y $312 \mathrm{~nm}$ ): la frecuencia estándar en la fase de inducción y consolidación es trisemanal (separadas por $\geq 24$ horas), aunque por los costos y las dificultades en el traslado puede considerarse bisemanal, con un tiempo de respuesta más lento ${ }^{11}$.

Puvaterapia (320-400 nm): consiste en la ingesta de 8 -metoxipsoraleno $(0,6 \mathrm{mg} / \mathrm{kg})$ o metoxaleno 0,5 $\mathrm{mg} / \mathrm{kg}$, antes de la exposición a la radiación UVA, de forma trisemanal, separadas por $\geq 48$ horas. No hay estudios en LCCT sobre la frecuencia de inducción. La fase de mantenimiento debe durar por lo menos 3 meses $^{11}$.

Puede combinarse con retinoides o interferón alfa $(\mathrm{INF}-\alpha)$ para optimizar la respuesta terapéutica ${ }^{1}$.

\section{Electron-beam corporal total (TSEB)}

Es una opción terapéutica segura y efectiva en el $\mathrm{SS}^{12}$. Los linfocitos T (LT) tumorales suelen responder a dosis bajas de radioterapia, que provoca su apoptosis ${ }^{3,5}$. La dosis total estándar es generalmente de 30-36 Gy en 
8-10 semanas, que suele dar altas tasas de remisión ${ }^{1,5}$. También se describen dosis menores (10-12 Gy), que permiten mejor tolerancia y la posibilidad de retratamiento, a pesar de una menor duración de la respues$\mathrm{ta}^{4}$. Introcaso et ál. demostraron, en 4 pacientes con SS tratados con TSEB, la resolución total de las manifestaciones cutáneas y la disminución de la carga tumoral en la sangre ${ }^{12}$. No obstante, su uso como monoterapia presenta recidivas frecuentes, por lo que se aconseja combinarla con otras terapéuticas ${ }^{3,11}$.

\section{TRATAMIENTOS SISTÉMICOS}

\section{Fotoféresis extracorpórea}

Es una terapia inmunomoduladora, considerada uno de los tratamientos iniciales de elección en el SS, aprobada por la FDA en $1988^{6-9,13,14}$. Si bien su eficacia se comprobó en múltiples trabajos científicos, como se trata de una entidad infrecuente no existen estudios prospectivos o ensayos clínicos aleatorizados con grupos control ${ }^{13,14}$. La guía europea la considera un tratamiento de primera línea en el SS y la micosis fungoide eritrodérmica. La fotoféresis extracorpórea se creó para tratar el LCCT, aunque luego se analizó su uso en otras entidades (enfermedad de injerto contra huésped, luego del trasplante alogénico de células madre, esclerosis sistémica, rechazo en el trasplante de órganos sólidos, enfermedad de Crohn, dermatitis atópica, etc. $)^{13}$.

El tratamiento consiste en la leucoféresis extracorpórea, la irradiación de los leucocitos con rayos UVA en presencia de 8-metoxipsoraleno y la reinyección al paciente. La fotoféresis provoca daño al $\mathrm{ADN}$, lo que conduce a la apoptosis de glóbulos blancos, en particular células NK y LT, que son fagocitados por células presentadoras de antígenos, con la consecuente activación del sistema inmunitario; se restaura la relación Th1/Th2, sin provocar inmunosupresión ${ }^{13,14}$.

La guía europea de fotoféresis extracorpórea recomienda un ciclo ( 2 días consecutivos) cada 2 semanas los primeros 3 meses de tratamiento, luego continuar con un ciclo cada 3 a 4 semanas ${ }^{13}$. El consenso de fotoféresis extracorpórea del Reino Unido y otros autores, como Zic et ál., sugieren iniciar con 2 días consecutivos cada 4 semanas y, en caso de empeoramiento, a los 3 meses de comenzado el tratamiento puede administrarse cada 2 semanas $^{14,15}$. Se interpreta como buena respuesta una mejoría mayor del $50 \%$ en los siguientes parámetros: disminución de las escalas de evaluación cutánea, del conteo de células de Sézary, de $\mathrm{CD}^{+}$o del clon maligno en la sangre periférica ${ }^{14}$.

Se consideran predictores de buena respuesta: leucocitos $<20.000 /$ microL, células de Sézary entre 10\% y $20 \%$, menos de 2 ańos del diagnóstico de SS, sin grandes adenopatías, ausencia de compromiso visceral, no haber recibido quimioterapia previa y sin aumento de células NK o de CD8 ${ }^{13}$.

La respuesta se evalúa cada 3 meses y debe mantenerse por lo menos durante 6 meses para considerarlo ineficaz ${ }^{13,14}$. Una vez lograda su máxima mejoría, se debe realizar el descenso progresivo a un ciclo cada 4 a 8 semanas de mantenimiento, por lo menos por más de 2 años $^{13}$. Molgo et ál. sugieren un ciclo cada 6 meses o un ańo como mantenimiento ${ }^{7}$.

En cuanto a las combinaciones, se aconseja esperar a los 3 meses de monoterapia con fotoféresis extracorpórea para agregar una terapia coadyuvante: INF, retinoides o tópicos ${ }^{7,13}$.

Presenta un buen perfil de seguridad, con una respuesta favorable en un $60 \%$ de los pacientes ${ }^{1}$. Los efectos adversos son infrecuentes y no suelen ser graves; se mencionan: hipotensión leve, pirexia posterior a la reinfusión de leucocitos, cefalea, fatiga y empeoramiento transitorio del prurito. ${ }^{7,13,14}$

\section{Interferón alfa (INF- $\alpha)$}

Las opciones son INF- $\alpha_{2 a}$ o INF- $\alpha_{2 b}$, los que difieren en un solo aminoácido en posición 23 , que no afecta la unión al receptor y poseen el mismo mecanismo de acción. La dosis puede variar entre 3 y 18 millones de unidades por vía subcutánea de forma trisemanal o diaria. En caso de que a los 6 meses no se observe una respuesta objetiva, debe aumentarse la dosis y, si ya se trata de la máxima tolerada por el paciente, se recomienda agregar o rotar a otra terapéutica ${ }^{16}$.

Una vez obtenida la respuesta completa, se indica mantener la dosis de INF- $\alpha$ por 3 meses más y luego descender de forma lenta la dosis o la frecuencia durante 6-12 meses $^{16}$.

Las tasas de respuestas globales varían ampliamente (rango de $0 \%$ a $80 \%)^{16}$. En un estudio de cohorte de 51 pacientes con micosis fungoide/SS tratados con INF- $\alpha, 11$ de ellos correspondían a SS, de los cuales el $25 \%$ presentaron una buena respuesta y $16,5 \%$ una respuesta completa, con una dosis media de $2,7 \mathrm{mi}$ llones UI/día ${ }^{17}$. Papa et ál. comprobaron la eficacia del INF- $\alpha_{2 a}$ utilizado como monoterapia en los LCCT, en un estudio prospectivo de cohorte de 43 pacientes. No obstante, solo mencionan una respuesta relativa en 2 de 6 (33\%) pacientes con SS del grupo que había recibido otros tratamientos previos, sin enunciar los resultados de aquellos que nunca fueron tratados ${ }^{18}$.

Los efectos secundarios son dependientes de la dosis. Se describen síntomas seudogripales, aumento de transaminasas, leucopenia y plaquetopenia, depresión, arritmias cardíacas y disfunción tiroidea ${ }^{1,3}$. 
Existen publicaciones sobre el uso combinado de INF y fotoféresis extracorpórea, con excelente respuesta global ${ }^{3}$.

El uso combinado de INF y retinoides está indicado cuando cualquiera de las dos terapéuticas por separado falló, o bien cuando no se dispone de INF + PUVA $^{1}$.

Está demostrada la seguridad y eficacia del uso combinado de INF- $\alpha$ y puvaterapia ${ }^{1}$. El primer estudio de esta combinación se realizó en 1990. Fue un ensayo en fase I que evidenció una respuesta completa en 12 de 15 pacientes con LCCT, de los cuales uno presentaba SS y que reflejó una rápida respuesta ${ }^{19}$.

\section{Bexaroteno}

Es un agonista sintético de los retinoides que actúa sobre el receptor RXR, lo que conduce a la inhibición de la proliferación tumoral y a la inducción de la apoptosis de las células de Sézary, con disminución de las citoquinas $T h 2^{3,8}$. Se utiliza en dosis de $300 \mathrm{mg} / \mathrm{m}^{2} /$ día por vía oral, que se puede aumentar o disminuir según la respuesta clínica y los efectos adversos, sin superar los 650 $\mathrm{mg} / \mathrm{m}^{2} / \mathrm{día}^{20}$. Las tasas de respuesta son muy variables, con un rango de respuesta objetiva (completa + parcial) entre $0 \%$ y $100 \%{ }^{3}$. En un ensayo multicéntrico de 26 centros, se trataron 94 pacientes en estadio avanzado del LCCT, de los cuales 17 correspondían a SS; la respuesta objetiva fue del $24 \%$ ( 4 de 17 pacientes) y ninguno de ellos presentó una respuesta completa ${ }^{21}$.

Los efectos adversos más frecuentes son la hipertrigliceridemia y el hipotiroidismo central, por lo que se recomienda el inicio, previo o concomitante, del tratamiento para la dislipidemia más hormonas tiroideas ${ }^{3}$. Panchal y Scarisbrick sugieren: el inicio de fenofibratos una semana antes de comenzar con el retinoide y la reposición de hormonas tiroideas desde el día 1 en una dosis de 25-50 $\mu \mathrm{g} /$ día, además de una dieta baja en grasas $^{20}$. También se describen: piel y mucosas secas, teratogenicidad, leucopenia, neutropenia, anemia, astenia, cefalea, náuseas, fotosensibilidad, diarrea y erupción cutánea ${ }^{3}$.

En general se indica combinado con otros tratamientos o como mantenimiento, ya que se considera seguro a largo plazo ${ }^{1,20}$. Las asociaciones más utilizadas con bexaroteno son: PUVA, INF- $\alpha$ y fotoféresis extracorpórea. Estas dos últimas, junto con el bexaroteno, constituyen una terapia triple aplicada en los LCCT eritrodérmicos ${ }^{20}$.

\section{Clorambucilo más prednisona}

Esta combinación se utiliza desde el año 1970 en el SS. El clorambucilo, en dosis de 2-6 mg/día, suele asociarse con prednisona $20 \mathrm{mg} /$ día inicialmente y luego se realiza el descenso a 0-10 mg/día ${ }^{1}$. La tasa de respuesta objetiva es alta (88-100\%), con una resolución completa que varía entre $0 \%$ y $45 \%{ }^{3}$.

\section{Inhibidores de la histona-desacetilasa (iHDAC)}

En el SS existe una expresión aumentada y una participación aberrante de la HDAC en las células cancerosas, por lo que los inhibidores de la HDAC resultan de utilidad. Entre ellos se encuentran: vorinostat, romidepsina y belinostat. En nuestro país se dispone del vorinostat, aprobado por la FDA para su uso en los LCCT persistentes, progresivos, recurrentes, o luego de haber recibido dos terapias sistémicas. Se indica 400 $\mathrm{mg} /$ día con las comidas, dosis bien tolerada y con rápido inicio de acción. Además de mejorar el compromiso cutáneo, hematológico y nodal, logra disminuir el prurito. Los efectos adversos más frecuentes son gastrointestinales, fatiga y trombocitopenia. La trombosis es el efecto secundario más grave. Se describen arritmias cardíacas: alteraciones en el segmento ST-T, prolongación del intervalo QTc, eventuales fibrilaciones auriculares $y$, menos frecuentes, taquiarritmias ventriculares, por lo que requieren control cardiológico ${ }^{8,22-24}$.

En un estudio multicéntrico en fase II, se trataron 74 pacientes con LCCT con vorinostat, de los cuales 30 presentaban SS. Estos últimos obtuvieron una tasa de respuesta del 30\% (10 de 30), ninguno de ellos presentó una respuesta completa ${ }^{22}$. Duvic et ál., en un estudio en fase II con menor número de pacientes, 33 en total y 11 de ellos con SS, demostraron una respuesta objetiva similar: $36 \%$ (4 de 11), sin lograr tampoco una respuesta completa ${ }^{23}$.

\section{Anticuerpos mononucleares}

Brentuximab vedotina: anticuerpo humanizado conjugado anti-CD30, que provoca el arresto del ciclo celular. Se administra $1,8 \mathrm{mg} / \mathrm{kg}$ por vía intravenosa cada 3 semanas por 16 ciclos $^{25}$.

ALCANZA es un ensayo clínico internacional en fase III, multicéntrico y aleatorizado, cuyo objetivo fue evaluar la eficacia y seguridad del brentuximab en comparación con la terapia estándar con metotrexato o bexaroteno en pacientes con LCCT CD30 ${ }^{+}$previamente tratados. Se demostró una respuesta objetiva global, que se mantuvo un mínimo de 4 meses, de $56 \%$ en el grupo de brentuximab contra $12 \%$ en el grupo de control ${ }^{26}$. Además, el primer grupo presentó una mayor tasa de respuesta completa, supervivencia sin progresión y disminución de los síntomas. Si bien los pacientes con micosis fungoide y SS con baja expresión de CD30 (<10\%) quedaron excluidos del tra- 
bajo, se demostró que respondieron al tratamiento con brentuximab ${ }^{26}$.

Los efectos adversos más frecuentes fueron neuropatía periférica $(66 \%)$, fatiga $(47 \%)$, náuseas $(28 \%)$, alopecia $(22 \%)$ y neutropenia $(19 \%)^{25}$.

\section{Quimioterapia}

Se describen esquemas de monoquimioterapia y poliquimioterapia (Tabla 3$)^{27}$. Presentan tiempos de respuesta rápidos, pero a expensas de inmunosupresión y toxicidad, sin repercusión en la supervivencia ${ }^{3,10}$.

En un estudio retrospectivo que incluyó a 198 pacientes con micosis fungoide/SS que recibieron tratamiento sistémico, tanto la monoterapia como la poliquimioterapia evidenciaron una duración limitada del control de la enfermedad. Se estudió en los pacientes el tiempo hasta el próximo tratamiento, que fue mayor en los tratados con INF- $\alpha$ y con los inhibidores de la HDAC en comparación con la quimioterapia $(8,7 ; 4,5$ y 3,9 meses, respectivamente). Por este motivo, los autores del estudio concluyeron que la quimioterapia solo debe considerarse en los pacientes refractarios al resto de las opciones terapéuticas ${ }^{27}$.

EPOCH: etopósido, vincristina, doxorrubicina, ciclofosfamida y pred-
nisolona
CHOP: ciclofosfamida, doxorrubicina, vincristina y prednisolona
Fludarabina + INF- $\alpha$
Fludarabina + ciclofosfamida
Gemcitabina
Doxorrubicina liposomal
Dosis bajas de metotrexato
Pralatrexato

TABLA 3: Quimioterapia.

\section{Metotrexato}

Zackheim et ál. trataron a 17 pacientes con diagnóstico de SS con bajas dosis de metotrexato (10-35 $\mathrm{mg} / \mathrm{semana}$ por vía intramuscular u oral) por 5 ańos, de los cuales $41 \%$ presentaron una respuesta completa y $35 \%$, una mejoría de la dermatosis mayor del $50 \%$. Además, la mejoría clínica se relacionó con la disminución de las células de Sézary circulantes. La supervivencia a los 5 ańos de estos pacientes fue del $71 \%{ }^{28}$. En el consenso de tratamiento de la EORTC, la dosis sugerida es de $5-25 \mathrm{mg} /$ semanal $^{1}$.

Se describen como efectos adversos: náuseas, vómitos, mucositis, úlceras bucales, leucopenia, anemia, trombocitopenia y aumento de las transaminasas 5 .

\section{Trasplante de médula alogénico}

Es el único tratamiento que podría llegar a ser curativo. Se describen períodos de remisión prolongados en algunos pacientes con micosis fungoide/SS ${ }^{1,3,5,10}$. Tiene la desventaja de ocasionar una morbimortalidad significativa, por lo que los pacientes deben ser adecuadamente seleccionados ${ }^{8,27}$. En un estudio retrospectivo, que incluyó a 8 pacientes con micosis fungoide y SS, todos los pacientes presentaron una respuesta clínica y hemática completa dentro de los 30-60 días del trasplante. Dos murieron por enfermedad de injerto contra huésped y por neumonía secundaria al virus sincicial respiratorio. Después de un seguimiento de 56 meses, los 6 pacientes restantes no presentaban evidencia de enfermedad ${ }^{29}$.

El consenso de la EORTC no aconseja el trasplante autólogo, ya que tiene alta morbimortalidad y no presenta remisiones duraderas ${ }^{1}$.

En la Tabla 4 se resumen las dosis y efectos adversos de los principales tratamientos sistémicos del SS.

\begin{tabular}{|c|c|c|}
\hline $\begin{array}{l}\text { Trata- } \\
\text { miento }\end{array}$ & Dosis & Efectos adversos \\
\hline INF- $\alpha$ & $\begin{array}{l}3 \text { a } 18 \text { millones de } \\
\text { unidades SC, de forma } \\
\text { trisemanal o diaria }\end{array}$ & $\begin{array}{l}\text { Síntomas seudogripales } \\
\text { Aumento de transaminasas, } \\
\text { leucopenia y plaquetopenia } \\
\text { Depresión } \\
\text { Arritmias cardíacas } \\
\text { Disfunción tiroidea }\end{array}$ \\
\hline Bexaroteno & $\begin{array}{l}300 \mathrm{mg} / \mathrm{m}^{2} / \text { día por vía } \\
\text { oral, modificada según } \\
\text { la respuesta clínica y } \\
\text { los efectos adversos. № } \\
\text { puede superar los } 650 \\
\mathrm{mg} / \mathrm{m}^{2} / \mathrm{dí}\end{array}$ & $\begin{array}{l}\text { Hipertrigliceridemia } \\
\text { Hipotiroidismo central } \\
\text { Piel y mucosas secas } \\
\text { Teratogenicidad } \\
\text { Leucopenia, neutropenia, } \\
\text { anemia } \\
\text { Astenia } \\
\text { Cefalea } \\
\text { Náuseas } \\
\text { Diarrea } \\
\text { Fotosensibilidad, erupción } \\
\text { cutánea }\end{array}$ \\
\hline Vorinostat & 400 mg/día por vía oral & $\begin{array}{l}\text { Gastrointestinales } \\
\text { Fatiga } \\
\text { Trombocitopenia } \\
\text { Trombosis } \\
\text { Arritmias cardíacas }\end{array}$ \\
\hline $\begin{array}{l}\text { Meto- } \\
\text { trexato }\end{array}$ & $\begin{array}{l}\text { 5-25 mg/semanal por vía } \\
\text { intramuscular u oral }\end{array}$ & $\begin{array}{l}\text { Náuseas, vómitos, mucosi- } \\
\text { tis, úlceras bucales } \\
\text { Leucopenia, anemia, } \\
\text { trombocitopenia y aumen- } \\
\text { to de las transaminasas }\end{array}$ \\
\hline $\begin{array}{l}\text { Brentuxi- } \\
\text { mab }\end{array}$ & $\begin{array}{l}1,8 \mathrm{mg} / \mathrm{kg} \text { por vía intra- } \\
\text { venosa cada } 3 \text { semanas } \\
\text { por } 16 \text { ciclos }\end{array}$ & $\begin{array}{l}\text { Neuropatía periférica } \\
\text { Fatiga } \\
\text { Náuseas } \\
\text { Alopecia } \\
\text { Neutropenia }\end{array}$ \\
\hline
\end{tabular}

TABLA 4: Dosis y efectos adversos de los principales tratamientos sistémicos. 


\section{TERAPIA DE MANTENIMIENTO}

Aunque no haya evidencia, la EORTC recomienda una terapéutica de mantenimiento luego de la respuesta al tratamiento instaurado, a fin de prolongar el tiempo sin enfermedad ${ }^{1}$. Para ello, se describen: fotoféresis extracorpórea, IFN- $\alpha$, dosis bajas de metotrexato, mecloretamina, PUVA, UVB, retinoides y glucocorticoides tópicos ${ }^{1,10}$.

Existen escasos estudios que valoran la eficacia de los antipruriginosos en el LCCT $^{30}$. Se observa una mejoría del prurito con el inicio del tratamiento ${ }^{30,31}$. La NCCN recomienda los antihistamínicos, doxepina y gabapentina como antipruriginosos de primera línea, mientras que la mirtazapina corresponde a una segunda opción y la naltrexona, a una tercera línea ${ }^{2}$. Brune et ál. trataron a 133 pacientes con prurito de diversas causas, entre ellas linfomas cutáneos, con naltrexona 50 a $150 \mathrm{mg} /$ día, con una tasa de respuesta del 64,6\%. Fue más efectiva en los pacientes con linfoma cutáneo, prurigo nodular y prurito de origen desconocido. Los autores concluyen que este antagonista opioide puede utilizarse en el prurito refractario de distintos orígenes ${ }^{32}$.

Olsen et ál. consideran, entre las primeras opciones, los antihistamínicos y la gabapentina. Esta última se indica entre 900 y $3600 \mathrm{mg} /$ día divididos en dos o tres tomas, lo cual produce sedación, efecto adverso buscado en los pacientes con SS. En caso de que los pacientes no logren aún conciliar el sueño con la gabapentina, se puede reemplazar la dosis de la tarde por mirtazapina 7,5 a $15 \mathrm{mg}^{3}$.

Meyer et ál. agregan los glucocorticoides, ya que mejoran el prurito en los pacientes con LCCT y sugie-

\section{BIBLIOGRAFÍA}

1. Trautinger F, Eder J, Assaf C, Bagot M, et ál. European Organisation for Research and Treatment of Cancer consensus recommendations for the treatment of mycosis fungoides/Sézary syndrome - Update 2017. Eur J Cancer 2017;77:57-74.

2. Mehta-Shah N, Horwitz SM, Ansell S, Ai WZ, et ál. Primary Cutaneous Lymphomas, Version 2.2020 Featured Updates to the NCCN Guidelines. J Natl Compr Canc Netw 2020;18:522-536.

3. Olsen EA, Rook AH, Zic J, Kim Y, et ál. Sézary syndrome: immunopathogenesis, literature review of therapeutic options, and recommendations for therapy by the United States Cutaneous Lymphoma Consortium (USCLC). J Am Acad Dermatol 2011;64:352-404.

4. Consenso Linfomas cutáneos primarios. Actualización 2019. Disponible en: <https://sad.org.ar/wp-content/ uploads/2019/09/Consenso-Linfoma-abril-2019.pdf> [Consulta: mayo de 2019].

5. Jawed SI, Myskowski PL, Horwitz S, Moskowitz A, et ál. Primary cutaneous T-cell lymphoma (mycosis fungoides and Sézary syndrome): Part II. Prognosis, management, and future directions. J Am Acad Dermatol 2014;70:223e1-223e17.

6. Trautinger F, Knobler R, Willemze R, Peris $\mathrm{K}$, et ál. EORTC ren una dosis de 10 a $30 \mathrm{mg} / \mathrm{día}$, con la desventaja de sus efectos adversos a largo plazo ${ }^{30}$.

\section{CONCLUSIONES}

Cabe destacar que si bien existen numerosas terapéuticas descriptas, en la actualidad no se dispone de un tratamiento estandarizado para el SS. Por este motivo, las dosis y la frecuencia de las terapias instauradas difieren entre los autores. Faltan ensayos clínicos prospectivos aleatorizados y controlados, dado que estamos frente a una entidad infrecuente, considerada una "enfermedad huérfana".

Una limitación en la búsqueda bibliográfica es que la mayoría de los trabajos publicados, sobre todo los referentes al tratamiento, incluyen a pacientes con LCCT o a grupos de pacientes con micosis fungoide/SS, de los cuales la mayoría de los casos corresponden a micosis fungoide y, en ocasiones, los resultados no son representativos para el SS. Además, algunos trabajos no distinguen la respuesta terapéutica por separado de ambas entidades. Otra crítica es que muchos de ellos se publicaron antes de la definición de SS y de la incorporación del compromiso hemático en la estadificación de micosis fungoide/SS en 2007. Asimismo, no hay evidencia científica sobre la terapia de mantenimiento recomendada por la EORTC.

Por último, existe unanimidad entre los autores de que se trata de una enfermedad incurable y que el principal objetivo del tratamiento es lograr una mejor calidad de vida y sobrevida de los pacientes, con remisiones clínicas más duraderas.

consensus recommendations for the treatment of mycosis fungoides/Sézary syndrome. Eur J Cancer 2006;42:1014-1030.

7. Molgo M, Jaque A, Vial V, Ocqueteau M, et ál. Fotoféresis en el tratamiento de síndrome de Sézary. Caso clínico. Rev Med Chile 2015;143:1449-1458.

8. Ram-Wolff C. Linfomas $\mathrm{T}$ cutáneos de tipo micosis fungoide/síndrome de Sézary (incluida parapsoriasis). EMCDermatología 2014;48:1-12.

9. Willemze $\mathrm{R}$, Hodak $\mathrm{E}$, Zinzani $\mathrm{PL}$, Specht $\mathrm{L}$, et ál. Primary cutaneous lymphomas: ESMO clinical practice guidelines for diagnosis, treatment and follow-up. Ann Oncol Off 2013;24:149-154.

10. Horwitz SM, Olsen EA, Duvic M, Porcu P, et ál. Review of the treatment of mycosis fungoides and Sézary syndrome: a stagebased approach. J Natl Compr Canc Netw 2008;6:436-442.

11. Olsen EA, Hodak E, Anderson T, Carter JB, et ál. Guidelines for phototherapy of mycosis fungoides and Sézary syndrome: A consensus statement of the United States Cutaneous Lymphoma Consortium. J Am Acad Dermatol 2016; 74: 27-58.

12. Introcaso CE, Micaily B, Richardson SK, Junkins-Hopkins JM, et ál. Total skin electron beam therapy may be associated with improvement of peripheral blood disease in Sézary syndrome. J Am Acad Dermatol 2008;58:592-595. 
13. Knobler R, Berlin G, Calzavara-Pinton P, Greinix H, et ál. Guidelines on the use of extracorporeal photopheresis. J Eur Acad Dermatol Venereol 2014;28:1-37.

14. Scarisbrick JJ, Taylor P, Holtick U, Makar Y, et ál. U.K. consensus statement on the use of extracorporeal photopheresis for treatment of cutaneous T-cell lymphoma and chronic graftversus-host disease. Br J Dermatol 2008;158:659-678.

15. Zic JA. Photopheresis in the treatment of cutaneous T-cell lymphoma: current status. Curr Opin Oncol 2012;24:1-10.

16. Olsen E. Interferon in the treatment of cutaneous T-cell lymphoma. Dermatol Ther 2003;16:311-321.

17. Jumbou $\mathrm{O}, \mathrm{N}^{\prime}$ Guyen $\mathrm{JM}$, Tessier MH, Legoux B, et ál. Longterm follow-up in 51 patients with micosis fungoides and Sézary síndrome treated by interferón-alfa. $\mathrm{Br} J$ Dermatol 1999;140:427-431.

18. Papa G, Tura S, Mandelli F, Vegna ML, et ál. Is interferon alpha in cutaneous T-cell lymphoma a treatment of choice? $\mathrm{Br} J$ Dermatol 1991;79:48-51.

19. Kuzel TM, Gilyon K, Springer E, Variakojis D, et ál. Interferon alfa2a combined with phototherapy in the treatment of cutaneous T-cell lymphoma. J Nat/ Cancer Inst 1990;82:203-207.

20. Panchal M, Scarisbrick JJ. The utility of bexarotene in mycosis fungoides and Sézary syndrome. Onco Targets Ther 2015;8:367-373.

21. Duvic M, Hymes $K$, Heald $P$, Breneman $D$, et ál. Bexarotene is effective and safe for treatment of refractory advanced-stage cutaneous T-cell lymphoma: multinational phase II-III trial results. J Clin Oncol 2001;19:2456-2471.

22. Mann BS, Johnson JR, Cohen MH, Justice R, et ál. FDA approval summary: vorinostat for treatment of advanced primary cutaneous T-cell lymphoma. Oncologist 2007;12:1247-1252.

23. Duvic $M, \mathrm{Vu} J$. Update on the treatment of cutaneous T-cell lymphoma (LCCT): focus on vorinostat. Biologics
2007:1:377-392.

24. Shah RR. Safety and Tolerability of Histone Deacetylase (HDAC) Inhibitors in Oncology. Drug Saf 2019;42:235-245.

25. Kim YH, Tavallaee $M$, Sundram U, Salva KA, et ál. Phase II investigator-initiated study of brentuximab vedotin in mycosis fungoides and Sézary syndrome with variable CD30 expression level: a multi-institution collaborative project. $J$ Clin Oncol 2015;33:3750-3758.

26. Prince $\mathrm{HM}$, Kim $\mathrm{YH}$, Horwitz $\mathrm{SM}$, Dummer $\mathrm{R}$, et ál. Brentuximab vedotin or physician's choice in CD30-positive cutaneous T-cell lymphoma (ALCANZA): an international, open-label, randomised, phase 3 , multicentre trial. Lancet 2017;390:555-566.

27. Hughes C, Khot A, Mc Cormack C, Lade S, et ál. Lack of durable disease control with chemotherapy for mycosis fungoides and Sézary syndrome: a comparative study of systemic therapy. Blood 2015;125:71-81.

28. Zackheim HS, Epstein EH Jr. Low-dose methotrexate for the Sezary syndrome. J Am Acad Dermatol 1989;21:757-762.

29. Molina A, Zain J, Arber DA, Angelopolou M, et ál. Durable Clinical, Cytogenetic, and Molecular Remissions After Allogeneic Hematopoietic Cell Transplantation for Refractory Sezary Syndrome and Mycosis Fungoides. J Clin Oncol 2005;23:6163-6171.

30. Meyer N, Paul C, Misery L. Pruritus in Cutaneous T-cell Lymphomas: Frequent, Often Severe and Difficult to Treat. Acta Derm Venereol 2010;90:12-17.

31. Görge T, Schiller M. Pruritus in Cutaneous T-cell Lymphoma. En Misery L, Stander S. Pruritus, Springer, Londres; 2010:121-124.

32. Brune $A$, Metze $D$, Luger TA, Ständer S. Antipruritic therapy with the oral opioid receptor antagonist naltrexone. Open, non placebo controlled administration in 133 patients. Hautarzt 2004;55:1130-1136. 
CUESTIONARIO DE EVALUACIÓN

1) Marque la opción correcta respecto del tratamiento del SS:

A- Es de elección la quimioterapia, ya que se trata de un linfoma de pronóstico ominoso.

B- Es de elección la monoterapia.

C- Se prefieren los tratamientos inmunomoduladores, ya que el principal objetivo es reducir al mínimo las recurrencias, preservar la calidad de vida y mejorar la supervivencia global. D-Se logra la curación en la mayoría de los pacientes si el tratamiento se instaura de forma temprana.

\section{2) ¿Cuál de los siguientes se considera de primera elección?}

A-Poliquimioterapia.

B-Trasplante de médula ósea.

C-Fotoféresis extracorpórea.

D- Alemtuzumab.

\section{3) Con respecto a la fototerapia:}

A- Provoca daño en el ADN y apoptosis de células tumorales.

B- Se describen tres fases: inducción, consolidación y mantenimiento.

C- Puede combinarse con retinoides o INF- $\alpha$ para optimizar su respuesta terapéutica.

D- Todas las opciones son correctas.

\section{4) ¿Cuál es la opción incorrecta sobre electron beam corporal total?}

A- Logra una rápida mejoría con remisiones duraderas.

B- La dosis total estándar es 30-36 Gy en 8-10 semanas, que suele dar altas tasas de remisión.

C-Los LT tumorales suelen responder a dosis bajas de radioterapia.

D- Su uso como monoterapia presenta recidivas frecuentes, por lo que se aconseja combinarla con otras terapéuticas.

\section{5) Fotoféresis extracorpórea:}

A-Solo está indicada en los linfomas cutáneos.

B- La gran ventaja de este tratamiento es su efecto inmunomodulador, sin provocar la inmunosupresión general del paciente. C- Se considera ineficaz si a los 2 meses de tratamiento el paciente no presenta respuesta.

D- No mejora la sobrevida de los pacientes con SS.

\section{6) En cuanto al interferón-alfa:}

A- Las tasas de respuesta son cercanas al $100 \%$.

B- Los efectos adversos no dependen de la dosis.

C-Está contraindicada su combinación con PUVA debido a que aumenta el riesgo de efectos adversos.

D- Suele administrarse inicialmente en una dosis de 3 millones de unidades subcutáneas, de forma trisemanal.

7) ¿Cuáles son los principales efectos adversos del bexaroteno?

A-Síntomas seudogripales.

B- Hipertrigliceridemia e hipotiroidismo central.

C- Fotosensibilidad.

D- Cefalea.

8) Marque la respuesta correcta sobre los inhibidores de la histona desacetilasa.

A- Aprobados por la FDA para su uso en LCCT persistentes, progresivos, recurrentes o luego de haber recibido dos terapias sistémicas. B-Son bien tolerados y con rápido inicio de acción.

C - La trombosis es el efecto secundario más grave.

D- Todas las opciones son correctas.

\section{9) En relación con el trasplante de médula alogénico:}

A- Es el único tratamiento que podría llegar a ser curativo.

B- Los pacientes deben ser adecuadamente seleccionados.

C-Es un procedimiento de baja morbimortalidad.

D- A y B son correctas.

10) ¿Cuál de las siguientes opciones es incorrecta con respecto al tratamiento del prurito?

A- Antihistamínicos, doxepina y gabapentina son considerados por la NCCN fármacos antipruriginosos de primera línea.

B- Se describe el uso de naltrexona 50 a $150 \mathrm{mg} /$ día, con una tasa de respuesta superior al $60 \%$.

C- La naltrexona es de primera línea.

D- Los glucocorticoides en dosis de 10 a $30 \mathrm{mg} /$ día logran una mejoría del prurito, con la desventaja de sus efectos adversos a largo plazo.

Respuestas correctas Vol. XXVI, N01, 2020

1.D/2.A/3. C/4.D/5.D/6.C/7.A/8.B/9.D/10.C 